\title{
UN Secretary-General's Message in Observance of World Environment Day, 5 June 1988
}

World Environment Day is observed-officially and at community level-once in a year. The observance, however, expresses an unremitting concern. Not a day passes without a reminder at one or more points of the globe that damage to our environment entails grave dangers to health, prosperity, and progress.

Crawling deserts, retreating forests, crumbling topsoil, disappearing or endangered species of plants and animals, the contamination of the atmosphere-these are among the more pronounced symptoms of that ecological violation which now threatens the natural system supporting human life. The realization is forcing itself upon the human conscience that the protection, rehabilitation, and improvement, of the environment, and the preservation of the world's natural resources, is one of the essentials of substainable development and of a just and stable world order.

The change in attitude and policy which has been induced by this world-wide awareness is cause for satisfaction. International cooperation to define and deal with the dangers to the natural surroundings of human life is improving. One of its most noteworthy results has been the conclusion last September of a major international agreement to protect the global environment. Under the auspices of the United Nations Environment Programme, the 'Montreal Protocol' was adopted to reduce the use of chem- icals that are damaging the ozone layer which protects life on Earth from excessive ultraviolet radiation.

It is only through such cooperation that we can address comprehensively the profound issue of change in the global climate due to the warming of the atmosphere by industrial and other economic activities. Desertification, deforestation, and many kinds of pollution, also call for global and regional agreements for action. The United Nations system is ready and qualified to provide the appropriate mechanisms for developing such international cooperation along a broad front.

Economic progress remains exposed to the danger of its reversal if nations cause a depletion of their natural resources and fail to provide for the generations to come. Repair and nurture of the environment open prospects of sound and balanced growth for peoples across the globe. This World Environment Day is once again an occasion for people everywhere, in both the industrialized and the developing countries, to dedicate themselves anew to a cause upon which our common future depends.

\author{
JAVIER PÉREZ DE CuÉLlar, Secretary-General \\ United Nations \\ New York City \\ NY 10017, USA.
}

\section{The CFC-Ozone Issue: Alternative Products and the Montreal Protocol*}

DuPont's recent decision to phase out the production of fully halogenated chlorofluorocarbons (CFCs) reaffirms our position that the Montreal Protocol is the most effective process for responding to recent advances in the science and for controlling global emissions of CFCs.

DuPont is committed to an orderly transition to the total phaseout of fully halogenated CFCs by the turn of the century. Also, we are urging all nations to accelerate ratification of the Montreal Protocol, and then immediately initiate the Protocol's assessment process to consider additional steps that would accomplish a total phaseout in a timely manner.

\section{DuPont's Position}

As it has evolved over the years, DuPont's position on the CFC-ozone issue has consistently been based on the best available scientific information. Until very recently, we concluded that atmospheric science and computer modelling projections did not support the call for actions to reduce CFC emissions. That position was in turn supported by the 1985 World Meteorological Organization report which concluded that there had been no statistically significant deterioration in protection afforded by the ozone layer. The WMO report also noted the prediction of computer models that, for current production-levels of CFCs, changes in ozone would be within the magnitude of those observed due to natural causes.

In September 1986, based on projections that CFC production and emissions could double in the next century, coupled with improved understanding of the growing body of scientific information, DuPont began advocating global emission controls. We also stated publicly our strong support for world-wide adoption of the Montreal Protocol as the most effective response to this global issue.

\footnotetext{
* See also Dr Glas's 'DuPont Position Statement on the Chlorofluorocarbon-Ozone-Greenhouse Issues', published in our Winter issue of 1986 (Vol. 13, No. 4, pp. 363-4). - Ed.
}

On 15 March 1988, NASA's Ozone Trends Panel announced new scientific findings which led to our current position that additional steps should be taken to protect the ozone layer on a global basis. For DuPont, that translates to a total phaseout of fully halogenated CFC production by the turn of the century.

\section{Alternative Products}

CFCs have become a widely-used product because they provide a 'safe' and effective way of accomplishing a variety of tasks demanded by society. These uses range from refrigeration for the production and distribution of food, blood, and biological matter, to air-conditioning for homes and office buildings, and to cleaning electronic components and sterilizing medical devices.

Because of the societal importance of these compounds, it is important that the transition to alternatives be accomplished in a safe and orderly fashion. As cooperative efforts will be critical in minimizing economic disruptions which could otherwise result, we have asked the user-industries and other CFC producers to join us in pursuit of this goal.

\section{Role of the Montreal Protocol}

Because it involves a global consensus-building process, the Montreal Protocol is a key element in the timely and safe adoption of alternative products. The current provisions of the Protocol call for a freeze in consumption of fully halogenated CFCs at 1986 levels in mid-1989, followed by a $20 \%$ reduction in mid-1993, and an additional $30 \%$ reduction by mid -1998 .

The Protocol negotiators developed these provisions with the understanding that they represented aggressive but achieveable goals. Recognizing the difficulty of predicting the rate of development and adoption of alternatives, the negotiators also specified an assessment process for reviewing the provisions in the light of new developments in the science. 